\title{
ENTRE O FICCIONAL E O DOCUMENTAL: VERSÕES DA DESIGUALDADE EM ÔNIBUS 174 (2002), DE JOSÉ PADILHA, E ÚLTIMA PARADA 174 (2008), DE BRUNO BARRETO
}

\author{
Ângela Srocynski da Costa ${ }^{1}$ \\ Rosângela Fachel de Medeiros ${ }^{2}$
}

\begin{abstract}
Resumo: Este trabalho propõe uma análise comparatista da representação da desigualdade social em sua relação com a violência no documentário Ônibus 174 (2002), de José Padilha, e no filme A última parada 174 (2008), de Bruno Barreto. Ambas as obras abordam um evento real que aconteceu no ano de 2000, no Rio de Janeiro, o sequestro do ônibus 174 realizado pelo jovem contraventor de nome Sandro. O evento foi completamente transmitido ao vivo pelas redes de televisão e culminou com o desfecho trágico e traumático da morte de uma das reféns por um tiro da polícia. Longe das câmeras, dentro do carro da polícia, no trajeto para a delegacia, Sandro é assassinado. O número do ônibus, mostrado tantas vezes durante a transmissão, está no nome das duas obras e serve de refrente para ambas as narrativas, uma vez que identifica uma região e uma realidade social. $A$ análise dos objetos se focará na forma como são apresentados os moradores de rua e de regiões periféricas, e a forma como essas representações ajudam a constituir o discurso sobre o crime, a criminalidade e a constituição desse jovem criminoso que acaba por ser assassinado.
\end{abstract}

Palavras-chaves: Ônibus 174. A última parada 174. Audiovisual.

\begin{abstract}
This work proposes a comparative analysis of the representation of social inequality and the relation to violence in the documentary Ônibus 174 (2002), by José Padilha, and the movie A última parada 174 (2008), by Bruno Barreto. Both works approach a real event that happened in 2000, in Rio de Janeiro: a kidnapping of the bus 174 carried out by a young offender named Sandro. The event was broadcast completely live by television networks and led to a tragic and traumatic outcome, because one of the hostages died in a police shooting. Away from the cameras inside the police car, on the way to the police station, Sandro was murdered. The bus number, shown so often during the transmission, is the name of the two works and serves as a reference for both narratives, since they identifies a region and a social reality. The analysis of the objects will focus on how the homeless and peripheral regions are introduced, and how these representations help to constitute the discourse on crime, criminality and the constitution of this young criminal who ends up being murdered.
\end{abstract}

Keywords: Ônibus 174. A última parada 174. Audiovisual.

\footnotetext{
${ }^{1}$ Graduanda em Letras, pela Universidade Regional Integrada do Alto Uruguai e das Missões URI/FW pib19446@uri.edu.br

${ }^{2}$ Orientadora, professora do curso de Letras na Universidade Regional Integrada do Alto Uruguai e das Missões- URI/FW rosangelafachel@gmail.com
} 


\section{Introdução:}

O presente artigo surge do projeto: Cinemas Mercosulinos: Globalização, coprodução e identidades culturais, que tem por financiamento 0 fomento FAPERGS-PROBIC. Para o inicio das investigações pertinentes às identidades culturais, fora decidido dedicar o estudo a questões étnico-raciais, uma vez que essa temática é recorrente na região do Mercosul. O fato de este conteúdo estar presente em nosso cotidiano faz com que diversas obras cinematográficas tenham por objetivo relatar um acontecimento genuíno, ou seja, baseado em fatos reais.

Cumprindo com a idealização do projeto, buscamos dar visibilidade a problemática social existente nas produções brasileiras, deste modo, trouxemos um acontecimento nacional, que resultou na criação de duas obras cinematográficas: de um lado, uma obra que demonstra a veracidade dos fatos, de maneira documentada, Ônibus 174 (2002) de José Padilha e de outro, um longa-metragem que reconstrói a história baseando-se no seu desfecho trágico, A última parada 174 (2008) de Bruno Barreto.

Sendo assim, o artigo busca compreender a conversação entre o documentário e o ficcional, que acaba por demonstrar por dois vieses distintos a imagem do bandido, de modo que aponte as características para a construção do sujeito criminoso na sociedade.

\section{O ponto de partida}

As linhas desta história começaram a ser preenchidas pela mídia no dia 12 de junho de 2000, por volta das 14h20m na cidade de Rio de Janeiro. A nação brasileira parou para acompanhar através dos meios de comunicação um sequestro ocorrido em um ônibus na linha 174. O ônibus ficou interditado por cinco horas sob a mira de um revólver, por outro lado, bastou cinco horas para Sandro Barbosa do Nascimento, ficar mundialmente conhecido.

O relógio que apontou cinco horas começou a rodar quando Sandro entrou no ônibus da linha 174 e anunciou o assalto, que seguiu por uma interceptação de policiais que receberam uma denúncia. Um dos policiais entrou pela porta dianteira e 
o outro pela traseira, deixando tempo para que o motorista, o cobrador e alguns passageiros fugissem do ônibus e fazendo com que Sandro engatilhasse o revólver calibre 38 e apontasse para a cabeça de uma mulher, cuja qual ele tinha tomado como refém. Os policiais foram obrigados a sair do ônibus e o pânico tomou conta dos onze passageiros que ficaram mantidos como reféns.

O massacre passou por momentos de grande tensão que foram cobertos por diversos meios de comunicação, o Brasil inteiro assistia em tempo real o que estava acontecendo. Em ordem cronológica, os momentos de maior enfoque da história foram:

a) O momento em que Luciana Carvalho (primeira refém com a arma colocada na cabeça), foi obrigada a tentar dirigir o automóvel, com o não sucesso da moça, Sandro disparou o primeiro tiro contra o vidro do ônibus, intimidando fotógrafos e cinegrafistas que registravam tudo em tempo real;

b) Após a liberação do primeiro refém Willians de Moura, restaram apenas mulheres no ônibus e Sandro apontou a arma na cabeça de Janaina Neves (outra passageira que ele havia tomado como refém) obrigando ela a escrever na janela do ônibus, com batom, as seguintes frases: "Ele vai matar geral às seis horas" e "ele tem pacto com o diabo";

c) O terceiro momento foi à liberação de uma mulher chamada Damiana Nascimento Souza, que havia começado a passar mal. O mal estar dela ocasionou em um acidente vascular cerebral.

d) O quarto momento de alta tensão foi quando o assaltante prometeu que iria fazer Janaina caminhar 100 passos e no final dos passos iria atirar nela. Porém, Sandro apenas exigiu que os passageiros encenassem que havia ocorrido uma morte, e então, fingiu atirar em Janaina.

e) O clímax do sequestro foi quando Sandro, demonstrando estar bastante cansado, decidiu sair do ônibus com uma das reféns. Ele desejava usarGeísa Firmo Gonçalves como escudo e ao descer, um policial do Batalhão de Operações Policiais Especiais (BOPE) tentou acabar com todo aquele tumulto e na tentativa de alvejar Sandro, acabou errando o tiro e acertou a refém de raspão no queixo. A reação de Sandro foi de imediato, ocasionando três disparos nas costas da refém. 
f) Sem a presença de uma refém para intimidar os policias, Sandro foi interceptado e levado ao camburão, onde foi morto por asfixia.

Esse "grande" relato, ou, apenas essas informações, foram passadas a população brasileira através dos meios de comunicações midiáticos, ora, após ler essa quantidade de informações, quem irá olhar por um outro viés se não a de um bandido que deve ser preso?

Infelizmente, vivemos em uma realidade em que a mídia não se preocupa em analisar a genuinidade dos fatos, apenas possui o objetivo de informar, Denise Silva Macedo fala sobre isso em seu livro Discursos nas Práticas Sociais:

Para divulgar e culminar essas dinâmicas sociais, a mídia se apodera de um pretenso discurso neutro que, em principio, visa apenas informar, objetivamente, os fatos. Para isso, mobiliza jornalistas, repórteres e fotógrafos; filma; retrata e modaliza essas imagens. Vende informações que não se transformam em conhecimentos; cria conflitos e guerras e "verdades" (se necessário for); aumenta audiências; sensacionaliza; forma opiniões [...] Ainformação-serviço confunde-se com a informação-produto. Tudo isso vira objeto de venda, de audiência. A notícia ganha valor de mercado (MACEDO, p.93, 2010).

A descrição de Macedo sobre o discurso midiático referente à tragédia do ônibus 174, deixa clara a pouca importância que a mídia traz sobre assuntos como esse.

\section{O documentário}

Sabendo que a os discursos midiáticos mantêm-se neutros, algumas lacunas ficam em branco. Pouco resta ao espectador, que interpreta a situação como apenas mais um crime que deve ganhar a devida justiça, porém, a morte de Sandro deixa o sentimento de "justiça" como extrapolado aos olhos de uma parte da população. José Padilha surge para terminar um trabalho inacabado e ir atrás de uma história que a mídia esqueceu-se de pôr em pauta. 
Ônibus 174 demorou 18 meses para ser produzido, tendo sua data de lançamento no dia 6 de dezembro de 2002. O documentário surge como forma de mostrar à população cegada pela mídia, um outro lado da moeda, uma realidade que insiste em acontecer e talvez não seja culpa somente da mídia, mas de uma nação inteira que não procura abrir os olhos para os problemas sociais.

O documentário exibe toda a cobertura da mídia, porém, combina as cenas com o contraponto registrado pelo depoimento de quem pudesse falar, de quem vivenciara a realidade do garoto Sandro. Durante todos os cortes de cena que apontavam os depoentes falando diretamente para a câmera, houve o contraponto entre os relatos do carcereiro, da tia de Sandro, Julieta Rosa do Nascimento, da assistente social Yvone Bezerra e da mãe adotiva de Sandro, Elza da Silva, todos esses relatos apontam o fato de que Sandro não era capaz de matar ninguém.

O filme traz a certeza de que o assalto não era coma intenção de causar tumulto daquele tamanho,e que o desenrolar da história fora o principal motivo da tragédia. Além disso, o documentário tem a responsabilidade de desconstruir a visão que a população tinha daquele bandido e ele perde parcelas de culpa e ganha um novo olhar da sociedade que é construído com base em sua própria personalidade: jovem negro que viu sua mãe ser esfaqueada aos seis anos de idade, sem outra saída, virou morador de rua, Sandro é também mais uma vítima sobrevivente da chacina da candelária, episódio de massacre, que tirou a vida de vários meninos de rua.

A crítica que essa obra cinematográfica faz à sociedade, à criminalidade e à segurança pública é sem duvida nenhuma, a oportunidade de nos fazer pensar, para que assim possamos abrir os olhos para uma população minoritária que tem seu cotidiano excluído e invisível, principalmente nas mídias, onde a principal ideia disseminada nesses meios, é a construção de estereótipos, nos quais, as mídias tentam por si só, transmitir ideias de que a criminalidade se liga única e exclusivamente aos indivíduos periféricos da sociedade, ou seja, que não participam ativamente dela.

\section{A ficção}


Com o conhecimento de que por trás dessa história havia uma grande crítica social, oito anos depois dessa terrível tragédia, Bruno Barreto resolveu também dar voz a problematização do ocorrido e assim produziu o longa metragem Última parada 174 (2008), que diferente do documentário, não tem a obrigação de contar os fatos como eles realmente são: "Eu e o Braulio usamos a realidade só como ponto de partida. A proposta desde o inicio era construir uma história de ficção que funcionasse como uma reflexão emocionada da realidade que deu origem a história." (BARRETO, 2008, SP) ou seja, a diferença entre as duas obras, é que uma busca respostas entre os envolvidos e traz uma perceptível crítica em formato de documentário, do outro lado, a obra de Barreto vem para demonstrar através de encenações o que pode ter acontecido e o porquê.

O começo da história fictícia de Última parada 174, já é um resumo de uma das críticas sociais que o filme faz. Em ordem cronológica o filme irá apresentar a tragédia existente na vida de dois personagens que irão ser a base de todo o enredo. Primeiro um menino chamado Alessandro, que era apenas um bebê quando foi tomado dos braços de sua mãe que não tinha condições psicológicas de criá-lo, já que possuía um enorme problema com o uso de drogas e tinha constantes dívidas com os traficantes da periferia. Meleca, o chefão do crime organizado da favela, expulsa Marisa, mãe de Alessandro, da comunidade como forma de punição pelas dívidas referentes às drogas e toma o garoto de seus braços e passa a criá-lo. Após dez anos longe dos braços da mãe, Alessandro aparece sendo ensinado por Meleca a usar arma de fogo e que ele deve "ter ódio no coração" (transcrito do filme).

Segundo, um menino de dez anos chamado Sandro (Michel Gomes), que também perde a figura materna, tendo a infelicidade de ver sua mãe deitada ao chão, vítima de um assassinato. Nos primeiros momentos sem a existência dela, ele mora com sua tia, só que em seguida, ele decide fugir da casa dela para conhecer Copacabana, lugar onde sua mãe desejava trabalhar, desse modo, ele conheceu a Candelária, que viria ser sua moradia e onde ele passaria a ser chamado de "Alê".

Com o passar dos anos, ambos os "Alê's" cresceram e seguiram caminhos sustentados pela criminalidade. Alessandro perde seu pai adotivo em uma guerra do tráfico, ato que vira manchete dos jornais cariocas, o que acaba chamando atenção de Marisa, sua mãe que conseguiu superar os vícios e construiu uma nova vida ao lado de um pastor. Com a morte de Meleca, Marisa encontra a possibilidade de ir ao 
encontro do filho, porém, ele foge da favela para não acabar com o mesmo destino do pai. Sandro, por outro lado, vive de esmolas e roubos, tudo para sustentar os vícios e se alimentar.

O encontro dos dois garotos acontece na própria Candelária. De um lado Alessandro que surge para cobrar uma dívida de drogas de Patola (Douglas Silva), um dos meninos moradores de rua, e do outro Sandro que teria usado a droga que Patola deveria vender. Alessandro ameaça os dois e apresenta um prazo para entrega do dinheiro, só que quando o prazo estava para se expirar um carro parou na rua da Candelária e começou a atirar em todos os meninos a queima roupa, quando Alessandro chegou encontrou Patola morto e foi interceptado pela polícia que acabara de chegar para registrar a chacina.

Sandro e os poucos sobreviventes foram levados para um abrigo pela assistente social Walquiria (Anna Cotrin), apesar de ter sido salvo por ela, ele decide rouba-la e ir à procura de drogas, ao conseguir foi parado por um policial que o levou para uma internação em um estabelecimento educacional.

Dois Alê's, aos dezessete anos, presos por infrações se encontram no instituto com dívidas pendentes, porém, haverá a reconciliação.

\section{Invisibilidade Social}

A sociedade vive por alimentar pré-conceitos criando rótulos e disseminandoos, utiliza de uma determinada imagem humana para distinguir o bem do mal e tenta apagar a existência do que não agrega aos valores humanos que a própria sociedade põe-se no direito de criar e seguir. Virou de práxis saber quem faz e acontece, qual sua personalidade e quais suas características físicas, o criminoso recebe uma identidade.

É uma identidade construída e imaginada sobre tipos sociais específicos, quais sejam os negros, os mestiços, as mulheres, os pauperizados e os menores, cujo desenvolvimento intelectual psicológico supostamente seria questionável. Os negros seriam definidos como potencialmente perigosos (bandidos naturais) conforme seu grau de desenvolvimento na evolução das raças humanas, o que definiria sua relação 
cognitiva sobre as próprias ações e a impossibilidade da escolha, do livre arbítrio (TERRA, p.203, 2010).

As duas obras conversam entre si e assumem um papel de extrema importância social, uma vez que a mídia não exibe os bastidores da vida do sujeito e o cidadão não se coloca no lugar do próximo e exige uma "justiça" que serve apenas para quem participa do grupo maioritário dos grandes centros urbanos.

Nos momentos finais ao sequestro do ônibus, quando Sandro desce com a refém a sua frente e ocorre a sequência resultante de um erro policial, a multidão que se fazia presente correu para tentar linchá-lo, tudo transmitido ao vivo em rede nacional e depois utilizado para a criação das duas obras cinematográficas. Essa seria a melhor resposta ao criminoso? Existe um ideal hipócrita em preservar a vida apenas de quem faz parte da sociedade capitalista e existe também um egocentrismo no ato de julgar um sujeito construído pela realidade social.

[...] a sociedade capitalista (civilização) corrompe os sujeitos empobrecidos, não apenas nos momentos em que incita um consumo sobre o que não se pode ter, mas também na medida em que não fornece as condições educacionais necessárias para o pleno desenvolvimento (ROUSSEAU, apud TERRA, 2010, p.205).

A citação de Rousseau por Livia Maria Terra é uma clara realidade que ocorre nos grandes centros urbanos onde o pobre não tem vez e a história que vem a ser dramatizada de Sandro transmite isso com clareza. Garoto pobre, morador de rua que precisa encontrar uma forma para manter-se e na realização de um assalto se vê encurralado pelas autoridades, logo, as mídias televisivas aparecem e dão voz a ele, fazendo-o com que se torne protagonista de uma história. Por outro viés, quando Terra fala da questão educacional, surge uma indagação: onde estão as autoridades políticas para resolver a existência de moradores de rua? Sandro, ao perder sua mãe, cresceu nas ruas e não teve a oportunidade de se projetar em uma sociedade escolarizada de classe elevada.

Durante cinco horas Sandro tomou os passageiros como reféns, fingiu matar, mas não matou. A polícia tinha o papel de negociar, acabar com o tumulto, fazer justiça e salvar vidas, porém, acabou ocasionando em um desfecho trágico que 
acabou por resultar em duas mortes, sendo que apenas uma possui a devida visibilidade.

\section{Considerações finais}

O estudo acerca destas obras não serviu como forma de proteger o indivíduo que causa calamidade social, mas foi a base para encontrar a desigualdade social e a construção do sujeito criminoso em nossa sociedade. O que segue para reflexão social é o fato que é necessária a desconstrução de estereótipos que insistem em fazer parte do nosso cotidiano.

Romper com o paradigma etiológico é romper com a visão de que existe um criminoso nato, e passar a ver essa figura como uma construção social que encerra em si diversos fatores, e que é mantida e legitimada por interesses de classe, próprios da sociedade capitalista. É, também, abrir espaços para qualificar o debate sobre a violência, para além do indivíduo. É perceber que seguindo o modelo criminológico da Escola Positiva não se discute a violência, ou melhor, discute-se apenas parte das relações de violência (XAVIER, 2008, p.280).

Jaime Ginzburg (1999) conclui em seu ensaio "A violência constitutiva: notas sobre autoritarismo e literatura no Brasil" que, "para a catástrofe, guardemos a perplexidade, a inquietação, jamais a linearidade ou a banalização". E a realização desta pesquisa mostrou que grande parte das narrativas tanto audiovisuais como literárias são capazes de mover inquietações que, se não provocarem mudança da realidade social de violência, podem incitar a uma mudança de postura de cada um dos receptores.

MACEDO, D, S. Documentário Ônibus 174: ama análise dos discursos e da multimodalidade do caos In: VIEIRA, J; BENTO, A; ORMUNDO, J. (orgs.). Discurso 
nas práticas sociais: perspectivas em multimodalidade e gramática sistêmicofuncional. São Paulo: Annablume, 2010.

SALVO, F, R. Cinema brasileiro e o boom dos filmes sobre favela: uma leitura de Última parada 174 como forma simbólica. Porto Alegre: Intexto, 2012.

BARRETO, bruno. Diretor de 'A última parada 174': Entrevista: Bruno Barreto fala sobre 'Última Parada 174'. UNICAMP. 22/10/2008.(entrevista concedida a Maria Alice da Cruz). Disponível em:http://www.unicamp.br/unicamp/noticias/entrevista-brunobarreto-fala-sobre-\%C3\%BAltima-parada-174. Acessado em: 27/03/2016

XAVIER, Arnaldo. A construção do conceito criminoso na sociedade capitalista: um debate para o serviço social. Katal, Florianópolis, jul/dez 2008, n.2, v.11, p.274-282.

TERRA, Livia Maria. Identidade bandida: A construção do estereótipo marginal e criminoso. Laboratório de Estudos da violência e segurança. Marília, dezembro/2010, n.6, p.196-208

GINZBURG, Jaime. A violência constitutiva: notas sobre literatura e autoritarismo no Brasil. Revista Letras, v. 18/19, Santa Maria, jan./dez. 1999, p. 121-144. 